\title{
Pengaruh Pemberian Ekstrak Kijing (Pilsbryoconcha exilis) Pada Pemulihan Kualitas Sperma Mencit (Mus musculus)
}

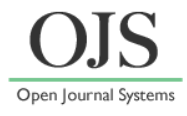

\author{
Erna Yunita Sari ${ }^{1 *}$, Bhakti Karyadi ${ }^{1}$, Aceng Ruyani ${ }^{1}$, Choirul Muslim ${ }^{2}$ \\ ${ }^{1}$ Pascasarjana Pendidikan IPA FKIP Universitas Bengkulu, Bengkulu \\ ${ }^{2}$ Jurusan Biologi FMIPA Universitas Bengkulu, Bengkulu \\ *Email: aqua_marin24@yahoo.com
}

DOI: https://doi.org/10.33369/pendipa.v3i1.6924

\begin{abstract}
[Effect of Kijing Extract (Pilsbryoconcha exilis) on the Recovery of Sperm Quality in Mice (Mus musculus)]. This study aims to determine the effect of Pilsbryoconcha exilis extract on the quality of $M$. muscullus sperm. The approach used for the study was experiment with a complete randomized design model. In this study, 4 treatments and 5 replications were conducted, including treatment 1 which only administered aquades as control (P0), treatment 2 which only given paracetamol dose $250 \mathrm{mg} / \mathrm{kg}(P 1)$, and treatment 3 given paracetamol dose $250 \mathrm{mg} / \mathrm{kg}$ and P. exilis extract dose 0,46 $\mathrm{mg} / \mathrm{g}(\mathrm{P} 2)$ and treatment 4 given paracetamol $250 \mathrm{mg} / \mathrm{kg}$ and extract P. exilis $0,69 \mathrm{mg} / \mathrm{g}$ (P3). Technique of data analysis using qualitative descriptive and statistical test of One Way Annova parametry, and if obtained significant difference then continued statistic test of Smallest Real Difference. From the results of the study, it was found that $P$. exilis and paracetamol extract had no effect on sperm quality.
\end{abstract}

Keywords: Sperm; M. muscullus; extract P. exilis; paracetamol. (Received August 14, 2018; Accepted January 20, 2019; Published February 26, 2019)

\begin{abstract}
ABSTRAK
Penelitian ini bertujuan untuk mengetahui pengaruh pemberian ekstrak Pilsbryoconcha exilis terhadap kualitas sperma $M$. muscullus yang diberi parasetamol. Pendekatan yang digunakan untuk penelitian adalah eksperimen dengan model rancangan acak lengkap (RAL). Pada penelitian ini menggunakan 4 perlakuan dan 5 ulangan meliputi perlakuan 1 yang hanya diberikan aquades merupakan kontrol (P0), perlakuan 2 yang hanya diberikan parasetamol dosis $250 \mathrm{mg} / \mathrm{kg}$ bb (P1), dan perlakuan 3 yang diberikan parasetamol dosis $250 \mathrm{mg} / \mathrm{kg}$ bb dan ekstrak $P$. exilis dosisi $0,46 \mathrm{mg} / \mathrm{g}$ bb (P2) dan perlakuan 4 yang diberikan parasetamol $250 \mathrm{mg} / \mathrm{kg}$ bb dan ekstrak $P$. exilis $0,69 \mathrm{mg} / \mathrm{g}$ bb (P3). Teknik analisa data menggunakan deskriptif kualitatif dan uji statistik parametri One Way Annova, dan jika didapatkan perbedaan yang bermakna maka dilanjutkan uji statistic Beda Nyata Terkecil (BNT). Dari hasil penelitian diketahui pemberian ekstrak $P$. exilis dan parasetamol berepengaruh tapi tidak signifikan terhadap kualitas sperma.
\end{abstract}

Kata Kunci: Sperma; M. muscullus; ekstrak P. exilis; parasetamol.

\section{PENDAHULUAN}

Indonesia merupakan negara kepulauan yang dua per tiga luas wilayahnya merupakan wilayah perairan dan dengan sumber daya perairan yang berlimpah. Salah satu komoditas perairan yang melimpah keberadaannya di perairan adalah kerang. Berdasarkan Departemen Kelautan dan Perikanan (Departemen Kelautan dan Perikanan, 2007) produksi kerang-kerangan di Indonesia dari tahun 2002 hingga 2006 meningkat. Data produksi dari tahun 2002 hingga 2006 berturut-turut, yaitu sebesar 7 ton, 2.869 ton, 12.991 ton, 16.348 ton, dan 18.896 ton, namun komoditas ini belum optimum pemanfaatannya.

Kijing lokal (Pilsbryoconcha exilis) adalah salah satu jenis kerang yang belum dimanfaatkan secara optimum, Padahal kijing berpotensi sebagai obat. Hasil dari analisis komposisi kimia 
pada $P$. exilis ditemukan adanya kandungan unsur mineral mikro yaitu selenium (Trisyanti, 2009). Manfaat selenium diantaranya adalah untuk produksi sperma, pembantu antioksidan dalam meredam keganasan radikal bebas. Selenium yang terkandung dalam ekstrak $P$. exilis adalah salah satu mineral penting yang berperan dalam spermatogenesis (Sukandar dkk, 2014).

Di era sekarang obat-obatan banyak dijual bebas di apotik dan toko obat, sehingga banyak dari kita sering menggunakan obat-obatan tanpa pengawasan dokter. Salah satu obat yang beredar di masyarakata yaitu parasetamol. Parasetamol bersifat toksik di hati jika digunakan dalam dosis besar. Menurut Kresnawati (2013) pada dosis tinggi, parasetamol menyebabkan keracunan dengan manifestasi yang salah satunya yaitu meurunnya gula darah. Jika parasetamol digunakan dalam dosis berlebihan dan dalam jangka waktu yang lama pada ibu hamil, dapat menyebabkan penurunan kadar testosteron pada janin bisa menimbulkan efek negatif pada janin, antara lain kemandulan hingga risiko mengidap kanker testis (Skakkebaek dkk, 2001). Menurut penelitian yang dilakukan oleh Kristensen, dkk (2011) bahwa parasetamol adalah antiandrogenik. Penelitian tentang parasetamol sebagai salah satu contoh senyawa yang bisa menyebabkan gangguan pada sistem reproduksi, masih sangat kurang.

Berdasarkan uraian permasalahan dalam latar belakang tersebut di atas, maka penulis bermaksud untuk melakukan penelitian mengenai pengaruh ekstrak $P$. exilis terhadap pemulihan kualitas sperma mencit (Mus musculus) pada pemberian parasetamol

\section{METODE PENELITIAN}

\section{Rancangan Penelitian}

Pendekatan untuk penelitian sains yang digunakan adalah eksperimen dengan model rancangan acak lengkap (RAL). Pada penelitian ini menggunakan 4 perlakuan dan 5 ulangan meliputi perlakuan 1 yang merupakan kontrol, perlakuan 2 yang hanya diberikan parasetamol, dan perlakuan 3 dan 4 yang diberikan parasetamol dan ekstrak Pilsbryoconcha exilis.

\section{Objek Penelitian}

Objek yang digunakan dalam penelitian ini adalah mencit (Mus musculus) jantan dewasa. Jumlah objek penelitian yang digunakan adalah 20 ekor mencit dengan umur relatif sama sekitar \pm 3 bulan dengan berat $25-40 \mathrm{~g}$ dan masingmasing kelompok terdiri dari 5 ekor mencit.

\section{Tempat dan Waktu Penelitian}

Penelitian dilakukan di kandang pemeliharaan hewan coba dan laboratorium biologi, Universitas Bengkulu. Penelitian ini dilaksanakan pada bulan Desember 2015 dan November 2017.

\section{Alat}

Sonde lambung (alat gavage), timbangan analitik, kandang mencit khusus dengan tempat pakan dan minum, bak bedah dan dissecting set, hemositometer Improved Neubeuer, handcounter merk Kenko, mikroskop, object glass, cover glass, cawan petri, pipet tetes, kertas saring micropore, kamera digital dan tisue.

\section{Bahan}

Mencit jantan dewasa dengan berat badan 25-40 gram sebanyak 20 ekor, eksrak kijing, pakan mencit berupa pellet, sekam kayu, larutan $\mathrm{NaCl}$ fisiologis 0,9\%, pewarna Eosin dan Nigrosin, alkohol 70\% dan aquadest steril.

\section{Cara Kerja}

\section{Tahap Aklimasi Mencit}

Mencit sebanyak 20 ekor dengan berat berkisar antara 25-40 gram dipelihara selama 2 hari di dalam kandang yang terbuat dari plastik dengan penutup dari kawat besi. Pada tiap-tiap kandang berisi 5 ekor mencit. Semua mencit diberi makan AD-II pellet dan minum secaraad libitum.

\section{Konversi Dosis}

\section{1) Dosis Parasetamol}

Dosis toksik parasetamol yang diinduksikan pada mencit menurut Sinta (2013) adalah $250 \mathrm{mg} / \mathrm{Kg}$ bb. Larutan parasetamol akan dioralkan ke $M$. musculus disesuaikan dengan berat badan mencit dikalikan dengan dosis obat $(0,25 \mathrm{mg} / \mathrm{g}$ bb $)$ dikalikan lagi dengan larutan stok 
(10 mL) kemudian dibagi dengan parasetamol (500 mg) sehingga didapat volume larutan untuk dioralkan ke M. musculus.

\section{2) Dosis Ekstrak Kijing}

Menurut Sinta (2013) dosis bahan uji yang digunakan yaitu berdasarkan pada kebiasaan penggunaan kijing sebagai obat yaitu 1 mangkok (masih dengan kulit) setiap kali makan, setara dengan berat $\pm 500 \mathrm{~g}$ atau $\pm 100 \mathrm{~g}$ tanpa kulit. $100 \mathrm{~g}$ kijing tersebut diekstraksi sehingga menghasilkan ekstrak murni. Jika kijing sebanyak 100 gr ini diekstraksi didapat 11,3807 gr ekstrak murni Dari ekstrak murni tersebut di konversikan pada dosis yang digunakan untuk manusia dengan berat $\pm 50 \mathrm{~kg}$, adalah:

$$
\begin{gathered}
\frac{\text { Ekstrak murni dari } 100 \mathrm{gr} \text { P.exilis }}{\text { berat badan manusia }(g)} g \\
=\text { dosis pada manusia }(\mathrm{g} / \mathrm{g} B B)
\end{gathered}
$$

Maka dosis yang digunakan pada mencit adalah:

Berat dosis pada manusia $(\mathrm{g}) \times$ berat mencit $(\mathrm{g})=$ dosis ekstrak $P$. exilis untuk mencit (Untuk pemberian ekstrak P.exilis melalui oral (gavage) perlu pengenceran, adalah:

$$
\begin{gathered}
\frac{1000 \mathrm{mg}(\text { ekstrak })}{25 \mathrm{ml}(\text { air })}=\frac{\text { dosis }(\mathrm{mg})}{x} \\
x=\frac{\text { dosis X } 25 \mathrm{ml} \text { air }}{1000} \\
X=m l
\end{gathered}
$$

\section{c. Pengelompokan Hewan Uji}

Pada penelitian ini, hewan yang akan diberi perlakuan ialah $M$. musculus, dengan berat 25-40 g. Mencit dikelompokkan secara acak menjadi 4 perlakuan.

\section{Pelaksanaan Penelitian}

Penelitian ini dilakukan dengan mengamati kualitas sperma $M$. musculus yang meliputi konsentrasi, morfologi, viabilitas dan motilitas sperma. Teknik analisa data menggunakan deskriptif kualitatif dan uji statistik parametri One Way Annova, dan jika didapatkan perbedaan yang bermakna maka dilanjutkan uji Beda Nyata Terkecil (BNT).

\section{HASIL DAN PEMBAHASAN}

Penelitian kualitas spermatozoa mencit ini meliputi: 1) konsentrasi spermatozoa, 2) morfologi spermatozoa, 3) viabilitas spermatozoa dan 4) motilitas spermatozoa.

\section{Konsentrasi Spermatozoa}

Penghitungan konsentrasi spermatozoa dilakukan setelah diberikan perlakuan parasetamol dan ekstrak $P$. exilis. Rerata konsentrasi spermatozoa terlihat pada Tabel 1.

Tabel 1. Rerata Konsentrasi Spermatozoa Setelah Diberi Parasetamol dan Ekstrak P. exilis

\begin{tabular}{|c|l|c|c|}
\hline No & \multicolumn{1}{|c|}{ Perlakuan } & N & $\begin{array}{c}\text { Rerata Sperma } \\
\text { (juta/ml) } \pm \text { SD }\end{array}$ \\
\hline 1 & P0 (aquades) & 5 & $247,2 \pm 95,8$ \\
\hline 2 & P1 (parasetamol) & 5 & $171,4 \pm 15,24$ \\
\hline 3 & $\begin{array}{l}\text { P2 (parasetamol + } \\
\text { P.exilis 0,46 mg/g bb) }\end{array}$ & 5 & $213 \pm 24,32$ \\
\hline 4 & $\begin{array}{l}\text { P3 (parasetamol + } \\
\text { P.exilis 0,69 mg/g bb) }\end{array}$ & 5 & $218,4 \pm 22,65$ \\
\hline
\end{tabular}

Perbedaan rerata konsentrasi spermatozoa sangat terlihat pada kelompok perlakuan parasetamol (P1) dibandingkan dengan kelompok lainnya. Sementara pemberian peningkatan dosis ekstrak $P$. exilis cendrung meningkatkan konsentrasi sperma.

\section{Morfologi Spermatozoa}

Morfologi spermatozoa merupakan salah satu indikator untuk melihat kualitas spermatozoa. Tabel 2 menunjukkan rerata persentase morfologi spermatozoa tidak normal antar kelompok perlakuan.

Tabel 2. Rerata Morfologi Tidak Normal Setelah Diberi Parasetamol dan Ekstrak P. exilis

\begin{tabular}{|c|l|c|c|}
\hline $\begin{array}{c}\text { N } \\
\mathbf{o}\end{array}$ & \multicolumn{1}{|c|}{ Perlakuan } & $\mathbf{N}$ & $\begin{array}{c}\text { Morfologi Sprema } \\
\text { Tidak Normal }\end{array}$ \\
\hline 1 & P0 (aquades) & 5 & $25,4 \pm 3,71$ \\
\hline 2 & P1 (parasetamol) & 5 & $32,2 \pm 4,76$ \\
\hline 3 & $\begin{array}{l}\text { P2 (parasetamol + P. } \\
\text { exilis } 0,46 \mathrm{mg} / \mathrm{g} \mathrm{bb})\end{array}$ & 5 & $24,8 \pm 6,41$ \\
\hline 4 & $\begin{array}{l}\text { P3 (parasetamol }+P . \\
\text { exilis } 0,69 \mathrm{mg} / \mathrm{g} \text { bb) }\end{array}$ & 5 & $22,2 \pm 4,08$ \\
\hline
\end{tabular}

Terlihat bahwa jumlah morfologi tidak normal, dimana semakin rendah jumlah 
morfologi pada kelompok perlakuan pemberian ekstrak kijing dengan dosis yang semakin tinggi.

\section{Viabilitas Spermatozoa}

Indikator lain untuk mengetahui pengaruh pemberian ekstrak $P$. exilis terhadap kualitas spermatozoa setelah diberi parasetamol adalah viabilitas spermatozoa. Tabel hasil analisis di bawah ini menjelaskan perbedaaan rerata persentase viabilitas spermatozoa pada masingmasing kelompok perlakuan.

Tabel 3. Rerata Viabilitas Spermatozoa Mencit Setelah Diberi Parasetamol dan Ekstrak P. exilis

\begin{tabular}{|c|l|c|c|}
\hline No & \multicolumn{1}{|c|}{ Perlakuan } & N & $\begin{array}{c}\text { Rata-rata } \\
\text { viabilitas Sperma }\end{array}$ \\
\hline 1 & P0 (aquades) & 5 & $63,2 \pm 4,26$ \\
\hline 2 & P1 (parasetamol) & 5 & $44,4 \pm 7,76$ \\
\hline 3 & $\begin{array}{l}\text { P2 (parasetamol + } \\
\text { P.exilis 0,46 mg/g bb) }\end{array}$ & 5 & $56,6 \pm 6,87$ \\
\hline 4 & $\begin{array}{l}\text { P3 (parasetamol + } \\
\text { P.exilis 0,69 mg/g bb) }\end{array}$ & 5 & $58,4 \pm 2,07$ \\
\hline
\end{tabular}

Terlihat peningkatan viabilitas sperma pada pemberian dosis ekstrak $P$. exilis yang semakin tinggi yaitu P2 sebesar 56,6\% dan P3 sebesar $58,4 \%$.

\section{Motilitas Spermatozoa}

Motilitas juga menjadi indikator untuk mengetahui pengaruh pemberian parasetamol dan ekstrak $P$. exilis terhadap kualitas spermatozoa secara mikroskopis. Tabel 4 menjelaskan perbedaaan rerata persentase motilitas spermatozoa pada masing-masing kelompok perlakuan.

Tabel 4. Rerata Motilitas Spermatozoa Mencit Setelah Diberi Parasetamol dan Ekstrak P. exilis

\begin{tabular}{|c|l|c|c|c|}
\hline \multirow{2}{*}{$\begin{array}{c}\text { N } \\
\text { o }\end{array}$} & \multicolumn{1}{|c|}{ Perlakuan } & \multicolumn{2}{c|}{$\begin{array}{c}\text { Motilitas } \\
\text { Sperma }\end{array}$} & $\begin{array}{c}\text { N rata- } \\
\text { rata (\%) }\end{array}$ \\
\cline { 3 - 4 } & A & b & \\
\hline 1 & P0 (aquades) & 23,8 & 37,4 & 58,6 \\
\hline 2 & P1 (parasetamol) & 13 & 27,8 & 42,2 \\
\hline 3 & $\begin{array}{l}\text { P2 (parasetamol + } \\
\text { P.exilis 0,46 mg/g bb) }\end{array}$ & 13,8 & 37 & 50,8 \\
\hline 4 & $\begin{array}{l}\text { P3 (parasetamol + } \\
\text { P.exilis 0,69 mg/g bb) }\end{array}$ & 17 & 36,4 & 53,4 \\
\hline
\end{tabular}

Keterangan: kategori a (sperma bergerak lurus kemuka), b (sperma gerak lambat, sulit maju, tidak lurus)
Terdapat peningkatan motilitas dengan pemberian dosis ekstrak $P$. exilis yang semakin besar baik untuk kategori (a) spermatozoa bergerak cepat dan lurus ke depan, ataupun kategori (b) geraknya lambat atau sulit maju lurus atau bergerak tidak lurus.

Dari hasil pengamatan diperoleh bahwa rerata jumlah, viabilitas, morfologi dan motilitas spermatozoa mencit pada kelompok yang diberi parasetamol tanpa pemberian ekstrak $P$. exilis (P1) lebih rendah dibandingkan dengan kelompok perlakuan yang diberikan ekstrak $P$. exilis setelah diberi parasetamol. Hal ini diduga parasetamol telah mengganggu spermatogenesis pada mencit. Menurut Jhonson dan Everitt, (2000) spermatogenesis dipengaruhi oleh berbagai faktor endogen dan eksogen. Faktor endogen meliputi hormonal, psikologis, dan genetik. Faktor eksogen dapat berupa bahan kimia dan obat-obatan. Dalam hal ini, bahan kimia yang menjadi faktor eksogen adalah parasetamol.

Parasetamol merupakan obat analgetik non narkotika dengan cara kerja menghambat sintesis prostaglandin terutama disistem syaraf pusat. Jika sintesa prostaglandin terhambat maka akan menyebabkan terganggunya pembentukan sperma dan sekresi hormon testosteron karena pada pria prostaglandin berfungsi untuk merangsang pembentukan sperma dan sekresi hormon testosteron. Menurut Kristensen dkk, (2011) parasetamol dapat mengganggu perkembangan reproduksi dan keseimbangan hormonal pria. Parasetamol termasuk antiandrogenik yaitu zat yang bisa menurunkan kadar androgen. Pada hewan jantan ataupun manusia, androgen merupakan hormon kelamin utama (Ariyanto, dkk. 2016). Androgen merupakan hormon steroid yang sebagian besar dihasilkan oleh sel-sel Leydig testis yang bertanggung jawab pada sistem reproduksi terutama perkembangan vas deferens dan duktusduktus lain, perkembangan struktur reproduksi eksternal dan reproduksi spermatozoa (Campbell dkk, 2004). Jika fungsi androgen mengalami gangguan maka proses produksi spermatozoa pun akan terganggu dan menyebabkan jumlah spermatozoa yang dihasilkan dari spermatogenesis akan menurun. 
Dalam kondisi ini, tubuh membutuhkan aktifitas antioksidan untuk menangkal efek negatif dari parasetamol. Ekstrak $P$. exilis yang diberikan pada penelitian ini mengandung berbagai macam mikronutrien dan mineral yang berperan sebagai antioksidan. Ekstrak $P$. exilis mengandung zat besi, seng, vitamin (A, D, E dan $\mathrm{K}$ ), niasin, iodium dan selenium (Trisyanti, 2009). Selenium yang terkandung dalam ekstrak $P$. exilis bekerja secara sinergis dan simultan dalam menangkal pengaruh buruk dari parasetamol. Mekanisme perlindungan ini akan menjaga spermatogenesis agar berjalan normal, sehingga produksi sperma juga akan normal, baik itu dari konsentrasi atau jumlah sperma yang dihasilkan, morfologi sperma, daya hidup maupun daya gerak sperma (Danang, dkk. 2012).

\section{KESIMPULAN}

Ekstrak $P$. exilis dan parasetamol berpengaruh tetapi tidak signifikan terhadap kualitas spermatozoa $M$. musculus yang meliputi indikator konsentrasi, morfologi, viabilitas dan motilitas spermatozoa namun memiliki kecenderungan menurunkan kualitas sperma.

\section{DAFTAR PUSTAKA}

Ariyanto, D., Sumantadinata, K., \& Sudrajat, A. O. (2016). Diferensiasi kelamin tiga genotipe ikan nila yang diberi bahan aromatase inhibitor. Jurnal Riset Akuakultur, 5(2), 165-174.

Campbell, N.A., Reece, J.B., Mitchell, I.G. (2004). Biologi Edisi Kelima Jilid 3. Jakarta: Erlangga.

Danang, D. R., Isnaini, N., \& Trisunuwati, P. (2012). Pengaruh lama simpan semen terhadap kualitas spermatozoa ayam kampung dalam pengencer ringer's pada suhu 4 C. TERNAK TROPIKA Journal of Tropical Animal Production, 13(1), 47-57. Departemen Kelautan dan Perikanan. (2007). Sistem Informasi Data. Jakarta: Departemen Kelautan dan Perikanan.
Johnson, M.H dan Barry J. Everitt. (2000). Essential Reproduction Fifth Edition. United Kingdom: Blackwell Science.

Kresnawati. (2013). Bahaya kelebihan dosis parasetamol. http://health.kompas.com (diakses tanggal 25 Oktober 2015).

Kristensen D. M., U. Hass, L. Lesné, G. Lottrup, P. R. Jacobsen, C. Desdoits-Lethimonier,J. Boberg, J. H. Petersen, J. Toppari, T. K. Jensen, S. Brunak, N. E. Skakkebaek, C. Nellemann,K. M. Main, B. Jégou, $H$. Leffers. (2011). Intrauterine exposure to mild analgesics is a risk factor for development of male reproductive disorders in human and rat. Hum. Reprod. 26, 235-244.

Sinta, Barbara Desbi. (2013). Pengaruh ekstrak daun nangka kuning terhadap kadar SPGT dan SGOT hati mencit yang diinduksi parasetamol sbagai sumber belajar (LKS) berbasis konstruktivis di SMA $N$ Bingin Teluk. Bengkulu : Univrsitas Bengkulu.

Skakkebaek, N. E., Rajpert-De Meyts, E., and Main, K. M. (2001). Testicular dysgenesis syndrome: an increasingly common developmental disorder with environmental aspects. Hum. Reprod. 16, 972-978.

Sukandar, Prihartin Bruto, dkk. (2014). Pengaruh Iodium Dan Selenium Terhadap Jumlah Sel Spermatogonium Dan Struktur Histologis Tubulus Seminiferus Testis Tikus Wistar Hipotiroid. Magelang: Balai Litbang GAKI.

Trisyanti, Ridiah. (2009). Keajaiban Kerang. http://www.zierfischforum.at. (diakses tanggal 17 Oktober 2015) Universitas Negeri Padang Press. 